\title{
Preliminary analysis of surface temperature anomalies that preceded the two major Emilia 2012 earthquakes (Italy)
}

\author{
Kai Qin ${ }^{1,2}$, Lixin X. Wu ${ }^{2,3,{ }^{\star}}$, Angelo De Santis ${ }^{4,5}$, Gianfranco Cianchini ${ }^{4,6}$ \\ ${ }^{1}$ China University of Mining and Technology, College of Geosciences and Surveying Engineering, Beijing, China \\ ${ }^{2}$ China University of Mining and Technology, School of Environment Science and Spatial Informatics, Xuzhou, China \\ ${ }^{3}$ Beijing Normal University, Key Laboratory of Environmental Change and Natural Disasters, Ministry of Education, Beijing, China \\ ${ }^{4}$ Istituto Nazionale di Geofisica e Vulcanologia, Sezione Roma 2, Roma, Italy \\ ${ }^{5}$ Università di Chieti-Pescara 'G. d'Annunzio', Dipartimento Geotecnologie per l'Ambiente e il Territorio, Chieti Scalo, Italy \\ ${ }^{6}$ Università di Siena, Scuola di Dottorato in Scienze Polari, Siena, Italy
}

\author{
Article history \\ Received July 21, 2012; accepted September 13, 2012. \\ Subject classification:
}

Earthquake geology and paleoseismology, Seismology: Surveys, measurements, and monitoring, Earthquake interactions and probability.

\section{Introduction}

In the 1980 's, from an analysis of satellite images, Russian scientists reported on a short-term thermal infrared radiation enhancement that occurred before some medium-to-large earthquakes in central Asia [Gorny et al. 1988]. Since then, many researchers have been studying earthquake thermal anomalies with satellite remote sensing data [Qiang et al. 1991, Tronin 1996, Tramutoli et al. 2001, Ouzounov and Freund 2004, Saraf and Choudhury 2004, Aliano et al. 2008, Blackett et al. 2011]. Recently, abnormal surface latent heat flux [Dey and Singh 2003, Cervone et al. 2005, Qin et al. 2009, Qin et al. 2011, Qin et al. 2012], outgoing long-wave radiation [Ouzounov et al. 2007] and microwave radiation [Takashi and Tadashi 2010] have also been shown to precede earthquakes. To investigate the possible physical mechanisms of such satellite thermal anomalies, some studies conducted a series of detecting experiments on rock loaded to fracturing [Wu et al. 2000, Freund 2002, Wu et al. 2002, Wu et al. 2006a, Wu et al. 2006b, Freund et al. 2007], and some hypotheses have been proposed. These have included: leaking of pore-gas, and hence the resulting greenhouse effect [Qiang et al. 1995]; activating and recombining of $\mathrm{p}$-holes during rock deformation [Freund 2002]; release of latent heat due to near-surface air ionization [Pulinets et al. 2006], and stress-induced thermal effects due to friction and fluids [Wu and Liu 2009].

According to the Istituto Nazionale di Geofisica e Vulcanologia (INGV; National Institute of Geophysics and Volcanology), two major earthquakes with almost the same large magnitudes struck northern Italy, on the Po Plain in the Emilia Region. The first hit on May 20, 2012, at 02:03 UTC, with $\mathrm{M}_{\mathrm{L}} 5.9\left(44.89^{\circ} \mathrm{N}, 11.23^{\circ} \mathrm{E} ; 6 \mathrm{~km}\right.$ in depth), and the sec- ond on May 29, 2012, at 07:00 UTC, with $\mathrm{M}_{\mathrm{L}} 5.8\left(44.85^{\circ} \mathrm{N}\right.$, $11.09^{\circ} \mathrm{E} ; 10 \mathrm{~km}$ in depth). These caused a total of 27 deaths and widespread damage.

In this study, the long-term temperature data from both satellite and ground (with greater emphasis on the satellite data) have been used to determine whether there were thermal anomalies associated with this Emilia 2012 seismic sequence. In particular, the next section will be dedicated to describing both the data and the method of analysis. In Section 3, we provide the more significant results, which we discuss in Section 4, together with the main conclusions.

We acknowledge that this work cannot be exhaustive, as it will require more data and analyses. However, although further studies will be welcome, we are confident that we have done the best with the data at our disposal.

\section{Data and method}

It is well known that satellite thermal sensors cannot continuously obtain surface temperature data because of IR absorption by thick clouds. This can lead to missing possible surface thermal anomalies that precede earthquakes. Retrospective analysis (or reanalysis) integrates a variety of observation systems with numerical assimilation models to produce long-term continuous and spatially complete datasets, which have great advantages over data retrieved directly from satellite observations. The earlier version of this reanalysis, such as the National Centers for Environmental Prediction (NCEP)/National Center for Atmospheric Research (NCAR) Reanalysis Project, which is being jointly carried out by the NCEP and NCAR in the USA, has proven to be a valuable data source in earthquake thermal anomaly re- 

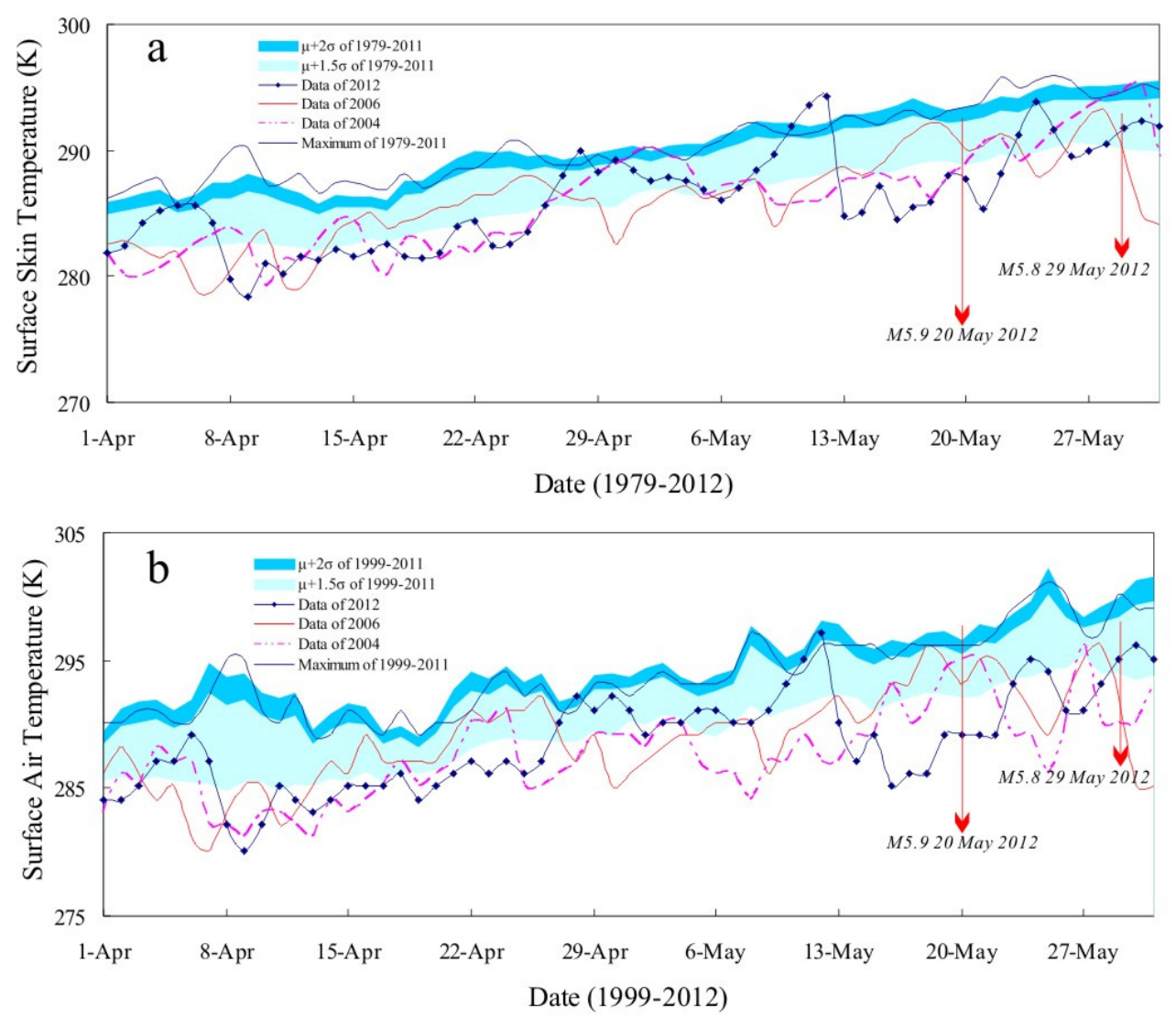

Figure 1. (a). The time series of surface skin temperature from MERRA for the area around the two major earthquakes epicenters $\left(44.5^{\circ} \mathrm{N}\right.$ to $46^{\circ} \mathrm{N}$, $10.5^{\circ} \mathrm{E}$ to $12^{\circ} \mathrm{E}$; red arrows indicate earthquakes time occurrences). (b). The time series of surface air temperatures from the weather ground station of Bologna $\left(44.53^{\circ} \mathrm{N}, 11.3^{\circ} \mathrm{E}\right)$, close to the epicenters.

search [Qin et al. 2012, Wu et al. 2012]. However, it is not suitable for seeking detailed analysis because of the lower spatio-temporal resolution.

Here, we use a new version of the reanalysis data, the Modern Era Retrospective-Analysis for Research and Applications (MERRA), which is a National Aeronautics and Space Administration atmospheric data reanalysis for the satellite era, using the Goddard Earth Observing System Data Assimilation System, version 5 (GEOS-5). As well as the observations from radiosondes, dropsondes and pilot balloons, MERRA makes extensive use of satellite radiance information, which includes data from hyper-spectral instruments, such as the Moderate Resolution Imaging Spectroradiometer on Aqua and Terra, Geosynchronous Operational Environmental Satellite sounders, and the Atmospheric Infrared Sounder on Aqua. The complete listing of the various data streams and their sources are documented fully in Rienecker et al. [2011]. The parameter investigated in this report is the surface skin temperature from the MERRA IAU Two-Dimensional Land Surface Diagnostics (MAT1NXLND) product, which is the MERRA two-dimensional hourly atmospheric single-level diagnostics, with a resolution of $2 / 3$ degrees longitude by $1 / 2$ degrees latitude. The Goddard Earth Sciences Data Information Services Center provides the hourly, daily and monthly files from 1979 to the present. According to the time of the appearance of a thermal anom- aly in previous earthquake case studies [e.g., Qiang et al. 1991, Tronin 1996] and the time of the Emilia seismic sequence, the surface skin temperature data in April and May of 1979-2012 were investigated.

First, long time series of surface skin temperature data for the area around the two major earthquakes epicenters $\left(44.5^{\circ} \mathrm{N}\right.$ to $46^{\circ} \mathrm{N}, 10.5^{\circ} \mathrm{E}$ to $12^{\circ} \mathrm{E}$; Figure 2 a, blue rectangular box) were analyzed. For the comparison of the data for 2012 with historical data, the mean $(\mu)$, standard deviation $(\sigma)$, and maximum were calculated using the multiple years data on the same day within the years preceding the earthquake sequence. Also, for confutation analysis, a comparison with the data of 2004 and 2006 is presented: 2004 and 2006 represent two particular years, without $\mathrm{M}>3$ earthquakes (according to the INGV catalog for this area). Also, a long time series of surface-air temperatures from the weather ground station of Bologna $\left(44.53^{\circ} \mathrm{N}, 11.3^{\circ} \mathrm{E}\right)$, which is close to the epicenters and is provided by the 'Weather Underground' website, have also been analyzed using the same method, for data accuracy validation and confutation. These latter data are available from 1999 to 2012.

Secondly, the spatial distributions of the daily surface skin temperature were analyzed. These are mainly controlled by climatological factors, such as latitude, seasons and terrain, and by weather factors, such as rain clouds and cold or hot air currents. Compared with the complex variation in the local 


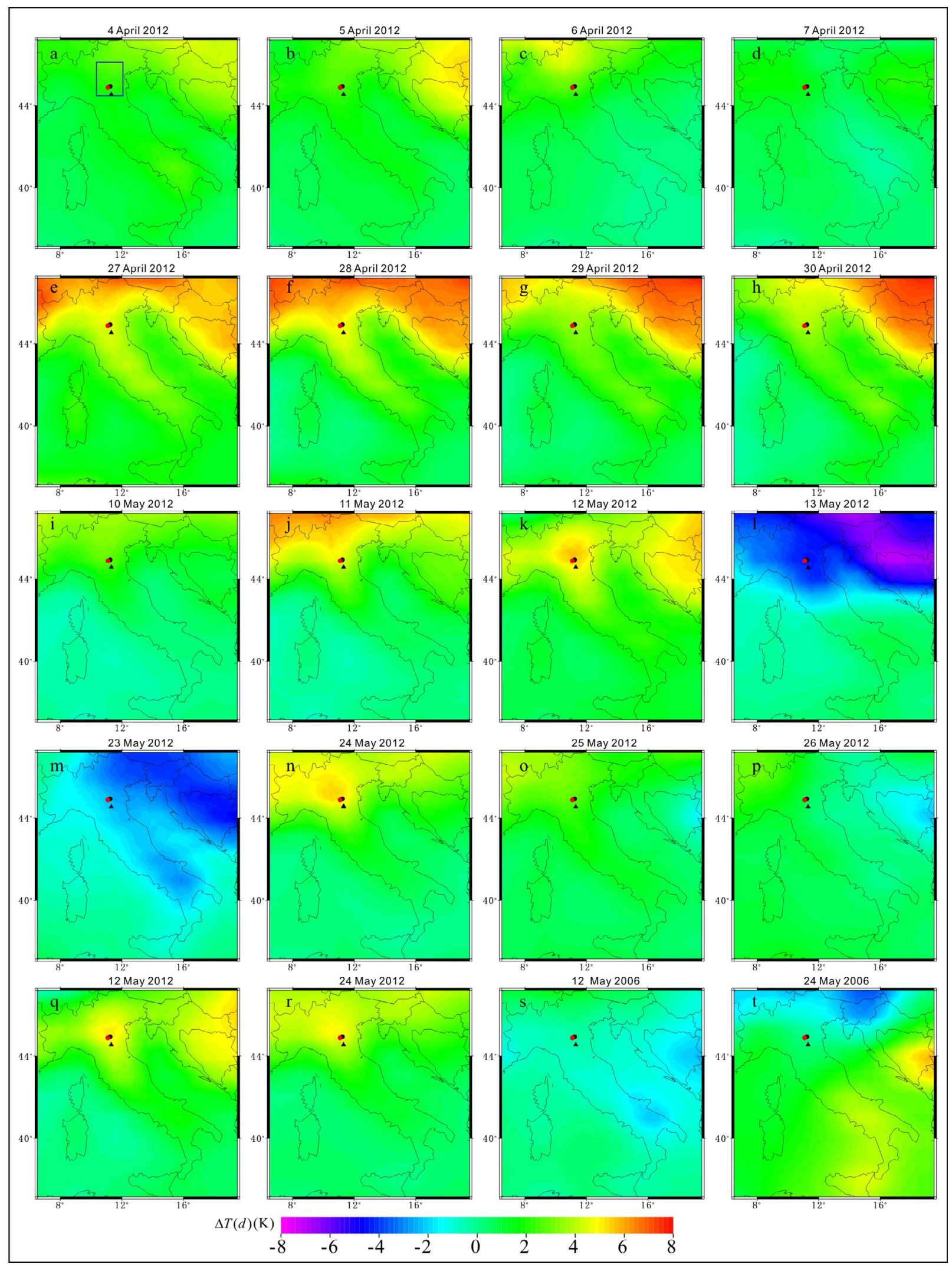

Figure 2. The spatial distributions of the changes in the daily temperature $(\Delta T(d))$ : a-h are obtained by subtracting the 33-year (1979-2011) mean of monthly temperature in April from the daily temperature $(T(d))$ on April 4-7 and 27-30, 2012, respectively; i-p are obtained by subtracting the 33-year (19792011) mean of monthly temperature in May from the $T(d)$ on May 10-13 and 23-26, 2012, respectively; $q$ is obtained by subtracting the 20-year (1992-2011) mean of the monthly temperature in May from the $T(d)$ on May 12, 2012; $\mathbf{r}$ is obtained by subtracting the 20-year (1992-2011) mean of the monthly temperatures in May from the $T(d)$ on May 24, 2012; $\mathbf{s}$ is obtained by subtracting the 33-year (1979-2011) mean of the monthly temperatures in May from the $T(d)$ on May 12 2006; $\mathbf{t}$ is obtained by subtracting the 33-year (1979-2011) mean of monthly temperature in May from the T(d) on May 242006 . The black and red points indicate the epicenters on May 20 and 29, 2012, respectively. The black triangles indicate the weather ground station of Bologna (44.53 ${ }^{\circ} \mathrm{N}$, $\left.11.3^{\circ} \mathrm{E}\right)$, close to the epicenters. The blue rectangular box in a indicates the area around the two major earthquakes epicenters $\left(44.5^{\circ} \mathrm{N}\right.$ to $46^{\circ} \mathrm{N}, 10.5^{\circ} \mathrm{E}$ to $12^{\circ} \mathrm{E}$ ) for the time series analysis. 
weather, the change in the climatological factors is much slower. We calculated the multiple years mean of the monthly temperature $(T(m))$ which represents a climatological background, and then subtracted the daily temperature $(T(d))$ from the $T(m)$, to get the change in daily temperature $(\Delta T(m))$ :

$$
\Delta T(d)=T(d)-\frac{1}{n} \sum_{i=1}^{n} T(m)_{i}
$$

where $T(d)$ is the daily temperature for 2012 (or for 2004 and 2006 , in the confutation analysis), and $T(m)_{i}$ is the corresponding monthly temperature within multiple years preceding the earthquake sequence.

Thirdly, the spatial distributions of the hourly surface skin temperatures were analyzed. We subtracted the hourly temperatures $(T(h))$ from the multiple years means of $T(h)$, which represent the climatological background, to get the change in hourly temperatures $(\Delta T(h))$ :

$$
\Delta T(h)=T(h)-\frac{1}{n} \sum_{i=1}^{n} T(h)_{i}
$$

where $T(h)$ is the hourly temperature of $2012 ; T(h)_{i}$ is the corresponding hourly temperature within the multiple years preceding the earthquake sequence.

\section{Results}

Although the daily temperature is affected by many factors, statistically, it will be limited to fluctuations within a certain range. Hence, those days on which the surface skin temperature (or surface air temperature) have values beyond $\mu+1.5 \sigma$ or maximum can be considered as candidate anomaly days. The time series of surface skin temperatures shows that there were eight candidate anomaly days in 2012, on April 5, 6, 28 and 30, and May 10, 11, 12 and 24 (Figure 1a). All of these candidate anomalies were higher than the corresponding days in 2004 and 2006, when no significant earthquakes occurred. The time series of surface air temperatures confirms all of these former anomalies, expecially for three of them (on April 28, and May 11 and 12, 2012) that showed greater statistical significance (Figure 1b).

After the statistical processing, we plotted the $\Delta T(d)$ images using the Generic Mapping Tools software. We especially focused on the spatio-temporal evolution of the $\Delta T(d)$ before and after the candidate anomaly days. We distinguished possible earthquake-induced temperature enhancements from the normal weather phenomenon by referring to the general conclusions of previous earthquake anomaly case studies [e.g., Qiang et al. 1991, Tronin 1996]: 1) the former generally presents a strip-shaped distribution related to the tectonic structure and/or active faults in the seismogenic zone, or spot-shaped distributions in the intersecting zone of tectonic faults and/ or around the epicenter, while the latter generally presents a wide-area consecutive and gradual distribution; 2) the former could appear at night time, while the latter is seldom at night time, without solar radiation.

From Figure $2 \mathbf{k}$ and $\mathbf{n}$, we find two spot-shaped anomalies with high amplitudes of about $6 \mathrm{~K}$ near the epicenters on May 12 and 24, 2012. The possible contributions from climatological factors are removed by subtracting the 33-year (1979-2011) mean $T(m)$ in May. To verify the stationarity of $T(m)$, we calculated the $T(m)$ using the 20-year (1992-2011) data, to get the $\Delta T(d)$ on May 12 and 24, 2012. As shown in Figure $2 \mathbf{q}$ and $\mathbf{r}$, in general the patterns are similar to Figure $2 \mathbf{k}$ and $\mathbf{n}$. The small isolated temporally limited 'hot spot' patch is quite unusual, in that it is a lot different from the wide-area consecutive and gradual weather effects, and cannot be found on May 12 and 24, 2004 and 2006 (for the sake of space, Figure $2 \mathbf{s}$ and $\mathbf{t}$ show only 2006), when there were no major earthquakes.

Furthermore, the $\Delta T(h)$ on May 12 and 24, 2012, show the detailed spatio-temporal evolution of the anomalies. As shown in Figure 3, two important considerations can be made: 1) from 20:00 to 23:00 UTC on May 12, 2012, an obvious hightemperature patch appeared, covering the epicenters, then gradually weakened and narrowed to the epicenters; 2 ) from 21:00 to 23:00 UTC on 24 May 2012, a slight high temperature spot appeared and was gradually enhanced near the epicenters. All of these appeared at local night time, confirming that the local high-temperature anomalies do not result from solar radiation enhancement, but are most likely associated with the Emilia 2012 seismic sequence.

\section{Discussion and conclusions}

Currently, the causes of earthquake thermal anomalies are not yet well understood. The mechanism of thermal anomalies preceding earthquakes might vary with cases, which are related to different seismogenic conditions and local ground cover (e.g., rock, desert, soil, vegetation, water). Bonfanti et al. [2012] considered that the significant thermal anomalies in central Italy preceding the L'Aquila 2009 seismic sequence could be attributed to the increase in green-house gas emission rates (e.g., such as for $\mathrm{CO}_{2}, \mathrm{CH}_{4}$ ). In addition, there were also other geophysical effects, such as the reactivation of p-holes, the upwelling of deep fluids [Cianchini et al. 2012], and the change in the atmospheric electric field. It is reasonable to expect that one or more of these phenomena might have occurred also in northern Italy preceding the Emilia 2012 seismic sequence. We believe that the mechanism is not merely single, but more likely multiple, due to the complex lithosphere-coversphere-atmosphere coupling in the seismogenic process [Wu and Liu 2009, Wu et al. 2012].

The statistical analysis of the MERRA surface skin temperature data of April and May 1979-2012 reveals that local temperature enhancements had appeared around the epicenters on the nights of May 12, 2012, i.e., 8 days before the May 20, 2012, $\mathrm{M}_{\mathrm{L}} 5.9$ earthquake, and of May 24, 2012, i.e., 5 days before the May 24, 2012, $\mathrm{M}_{\mathrm{L}} 5.8$ earthquake. This is in agreement with the surface air temperatures from the weather 


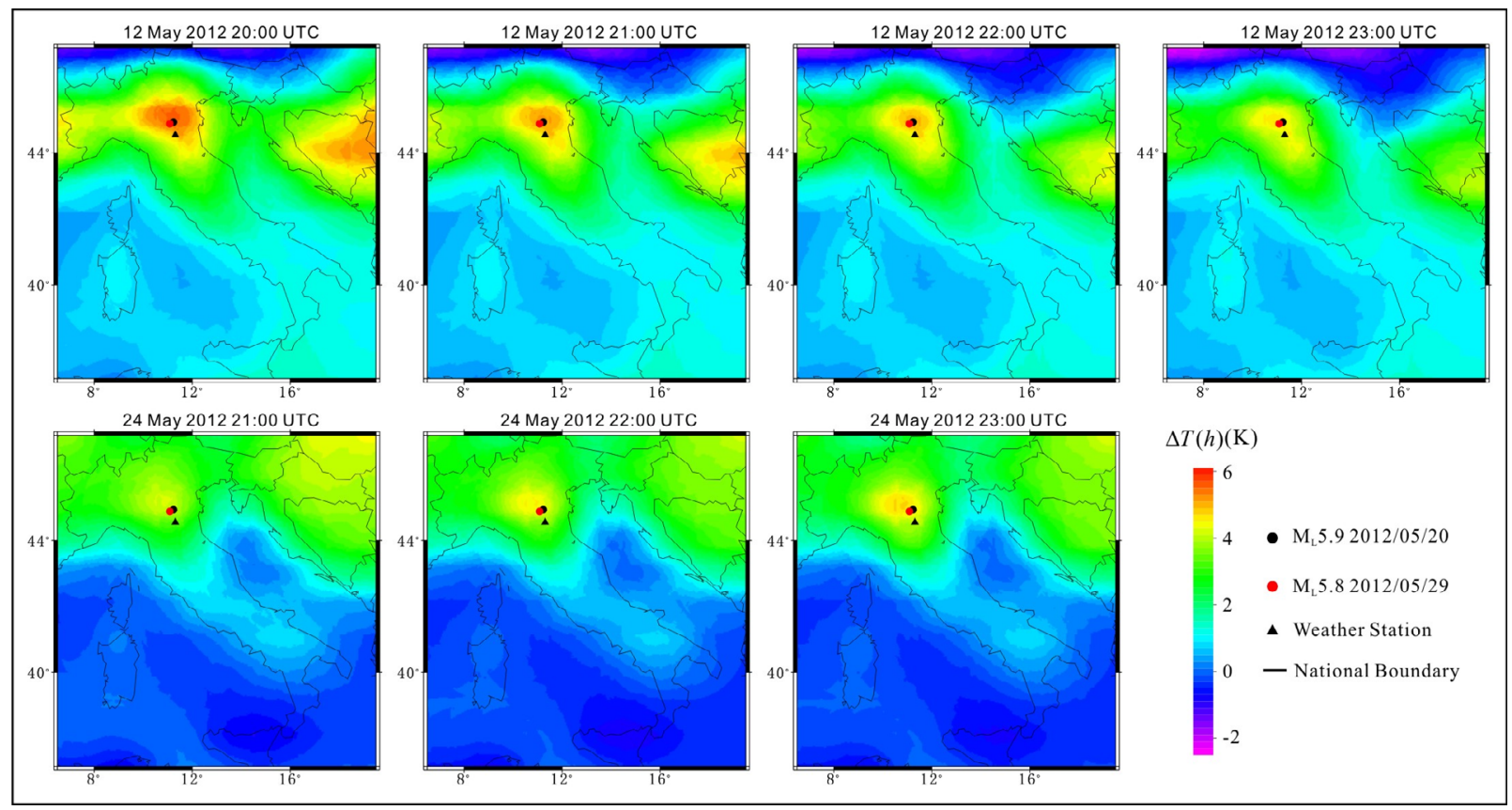

Figure 3. The spatial distribution of the change in hourly temperature $(\Delta T(h))$ at 20-23 UTC, May 12, 2012, and at 21-23 UTC, May 24, 2012, respectively. This was obtained by subtracting the 33-year (1979-2011) mean of the corresponding hourly temperatures, which represent the climatological background, from the corresponding hourly temperatures $(T(h))$ of 2012.

ground station close to the epicenters. The spatial patterns (location and shape) and the appearance time of the surface temperature anomalies show a possible association with the seismogenic process, and could be of precautionary significance for the events. However, because of the great complexity of the processes associated with the preparation of large-to-intermediate earthquake phenomena, a more multidisciplinary and integrated approach to the problem must be applied. This is like that indicated by geosystemics [De Santis 2009], where entropy and other analogous physical quantities are fundamental [De Santis et al. 2010, 2011].

The present study represents a preliminary, although significant, contribution to the understanding of the evolution of the Emilia seismic sequence in space and time. Therefore, further studies are suggested, including investigations into other thermal parameters (e.g., surface latent heat flux, outgoing long-wave radiation, microwave radiation) and the eventual localized process of lithosphere-coversphere-atmosphere coupling behind the thermal anomalies and precursory features.

Acknowledgements. This work was jointly supported by the National Basic Research Program of China (973 Program) (Grant No.2011CB707102) of the China Ministry of Science and the Technology, the National Natural Science Foundation of China (No. 41071280), the Program of Scientific and Technological Cooperation between Italy and China (SAGA-4-EPR), and the Project Funded by the Priority Academic Program Development (PAPD) of Jiangsu Higher Education Institutions. We acknowledge the USA Global Modeling and Assimilation Office, the Goddard Earth Sciences Data Information Services Center, and the website of 'Weather Underground', for providing data used in this study. We acknowledge the reviewers for helping us to improve the quality of the report. We thank Dr. Dimitar Ouzounov of Chapman University, USA, for useful discussion on the data analysis.

\section{References}

Aliano, C., R. Corrado, C. Filizzola, N. Genzano, N. Pergola and V. Tramutoli (2008). Robust TIR satellite techniques for monitoring earthquake active regions: limits, main achievements and perspectives, Annals of Geophysics, 51 (1), 303-318.

Blackett, M., M.J. Wooster and B.D. Malamud (2011). Exploring land surface temperature earthquake precursors: a focus on the Gujarat (India) earthquake of 2001, Geophys. Res. Lett., 38, L15303.

Bonfanti, P., N. Genzano, J. Heinicke, F. Italiano, G. Martinelli, N. Pergola, L. Telesca and V. Tramutoli (2012). Evidence of $\mathrm{CO}_{2}$-gas emission variations in the central Apennines (Italy) during the L'Aquila seismic sequence (March-April 2009), B. Geofis. Teor. Appl., 53, 147-168.

Cianchini, G., A. De Santis, D.R. Barraclough, L.X. Wu and K. Qin (2012). Magnetic transfer function entropy and the $2009 \mathrm{Mw}=6.3$ L'Aquila earthquake (central Italy), Nonlinear Proc. Geoph., 19, 401-409.

Cervone, G., R.P. Singh, M. Kafatos and C. Yu (2005). Wavelet maxima curves of surface latent heat flux anomalies associated with Indian earthquakes, Nat. Hazards Earth Sys. Sci., 5, 87-99.

De Santis, A. (2009). Geosystemics, In: Proceedings of the 3rd IASME/WSEAS International Conference on Geology and Seismology (GES'09), Plenary Lecture.

De Santis, A., G. Cianchini, E. Qamili and A. Frepoli (2010). The 2009 L'Aquila (central Italy) seismic sequence as a chaotic process, Tectonophysics, 496, 44-52.

De Santis, A., G. Cianchini, L. Beranzoli, P. Favali and E. Boschi (2011). The Gutenberg-Richter law and entropy 
of earthquakes: two case studies in central Italy, B. Seismol. Soc. Am., 101, 1386-1395.

Dey, S., and R.P. Singh (2003). Surface latent heat flux as an earthquake precursor, Nat. Hazards Earth Syst. Sci., 3, 749-755.

Freund, F.T. (2002). Charge generation and propagation in igneous rocks, J Geodyn., 33, 543-570.

Freund, F.T., A. Takeuchi, B.W.S. Lau, A. Al-Manaseer, C.C. $\mathrm{Fu}$, N.A. Bryant and D. Ouzounov (2007). Stimulated infrared emission from rocks assessing a stress indicator, eEarth, 2, 7-16.

Gorny, V.I., A.G. Sal'man, A.A. Tronin and B.V. Shilin (1988). Outgoing terrestrial infrared radiation as an indicator of seismic activity, Akademiia Nauk SSSR, Doklady (ISSN 0002-3264), 301 (1), 67-69 (in Russian).

Ouzounov, D., and F.T. Freund (2004). Mid-infrared emission prior to strong earthquakes analyzed remote sensing data, Adv. Space Res., 33, 268-273.

Ouzounov, D., D.F. Liu, C.L. Kang and P. Taylor (2007). The outgoing long-wave radiation variability prior to the major earthquake by analyzing IR satellite data, Tectonophysics, 421, 211-220.

Pulinets, S., D. Ozounov, A.V. Karelin, K.A. Boyarchuk and L.A. Pokhmelnykh (2006). The physical nature of thermal anomalies observed before strong earthquakes, Phys. Chem. Earth., 31, 143-153.

Qiang, Z.J. X.D. Xu and C.G. Dian (1991). Thermal infrared anomaly precursor of impending earthquakes, Chinese Sci. Bull., 36, 319-323.

Qiang, Z.J., L.C. Kong, M.H. Guo and Y.P. Wang (1995). Laboratory research on mechanism of satellite infrared anomaly, Chinese Sci. Bull., 16, 1403-1404.

Qin, K., G.M. Guo and L.X. Wu (2009). Surface latent heat flux anomalies preceding inland earthquakes in China, Earthquake Science, 22 (5), 555-562.

Qin, K., L.X. Wu, A. De Santis and H. Wang (2011). Surface latent heat flux anomalies before the $M_{S} 7.1$ New Zealand earthquake 2010, Chinese Sci. Bull., 56, 3273-3280.

Qin, K., L.X. Wu, A. De Santis, J. Meng, W.Y. Ma and G. Cianchini (2012). Quasi-synchronous multi-parameter anomalies associated with the 2010-2011 New Zealand earthquake sequence, Nat. Hazards Earth Syst. Sci., 12, 1059-1072.

Rienecker, M.M., et al. (2011). MERRA - NASA's ModernEra Retrospective Analysis for Research and Applications, J. Climate, 24, 3624-3648.

Saraf, A.K., and S. Choudhury (2004). Satellite detects surface thermal anomalies associated with the Algerian earthquakes of May 2003, Int. J. Remote Sens., 26, 2705-2713.

Takashi, M., and T. Tadashi (2010). Detection algorithm of earthquake-related rock failures from satelliteborne microwave radiometer data, IEEE T. Geosci. Remote, 48, 1768-1776.
Tramutoli, V., G.D. Bello, N. Pergola and S. Piscitelli (2001). Robust satellite techniques for remote sensing of seismically active areas, Annali di Geofisica, 44 (2), 295-312.

Tronin, A.A (1996). Satellite thermal survey-a new tool for the study of seismoactive regions, Int. J. Remote Sens., 41, 1439-1455.

Wu, L.X., C.Y. Cui, N.G. Geng and J.Z. Wang (2000). Remote sensing rock mechanics (RSRM) and associated experimental studies, Int. J. Rock Mech. Min., 37, 879-888.

Wu, L.X., S.J. Liu, Y.H. Wu and Y.Q. Li (2002). Changes in IR with rock deformation, Int. J. Rock Mech. Min., 39, 825-831.

Wu, L.X., S.J. Liu and Y.H. Wu (2006a). Precursors for rock fracturing and failure - part I: IRR image abnormalities, Int. J. Rock Mech. Min., 43, 473-482.

Wu, L.X., S.J. Liu and Y.H. Wu (2006b). Precursors for rock fracturing and failure-part II:IRR T-curve abnormalities, Int. J. Rock Mech. Min., 43, 483-493.

Wu, L.X., and S.J. Liu (2009). Chapter 34: Remote Sensing Rock Mechanics and Earthquake Infrared Anomalies, In: G. Jedlovec (ed.), Advances in Geosciences \& Remote Sensing, Sweden, In-Teh, 709-741.

Wu, L.X., K. Qin and S.J. Liu (2012). GEOSS-based thermal parameters analysis for earthquake anomaly recognition, In: Proceedings of the IEEE, 99, 1-17; doi:10.1109/JPROC. 2012.2184789.

${ }^{\star}$ Corresponding author: Lixin X. Wu, China University of Mining and Technology, School of Environment Science and Spatial Informatics, Xuzhou, China; email: awulixin@yahoo.com.cn.

C 2012 by the Istituto Nazionale di Geofisica e Vulcanologia. All rights reserved. 